\title{
The diagnosis and comparison of physical abilities of skiers and footballers
}

\author{
Vasilios F. Giovanis, Panagiotis V. Vasileiou, Evangelos M. Bekris \\ School of Physical Education and Sports Science, National and Kapodistrian University of Athens, Greece
}

\begin{abstract}
Purpose:

The purpose of this research was to diagnose the physical abilities such as speed, strength, agility and endurance of alpine skiers and footballers through the same country tests. Also, the purpose was to compare the performance and test results of the above tested against one another.

Material: $\quad$ The sample of 58 individuals came from two groups of men of different sports: skiing $(\mathrm{n}=29)$ aged 18-26 (20.97 \pm 2.08 years) and football $(n=29)$ aged $18-25(21,28 \pm 1.56$ years), while the level in each group was the advanced and the beginner respectively. Until the trials, the ski and football teams had a training program exercising physical abilities and skills three days a week for the specialties and one day a week the select skiing session and the compulsory football session according to the curriculum. In order to diagnose and compare the physical abilities of ski students and football students, the following four tests of Alpine skiing on dry ground were used after the ski season on this day in April 2014: A) Route speed test (route 20m with flight start). B) Explosive power tests of the lower limbs (eightfold with alternating tossing of feet). C) Agility Tests (Slalom's track on a "folder" $5 \mathrm{~m} \times 5 \mathrm{~m}$ ). D) Anaerobic test (jumping obstacle $20 \mathrm{~cm}$ height for $60 \mathrm{sec}$ ).

Results: In the skiing specialty we have a great correlation between speed tests and other physical abilities and agility with endurance $(r=-0,72)$. In football specialty there was a great correlation between speed and power tests $(r=-0.65)$ and agility with the power $(r=-0.69)$. In optional skiing, we have a moderate correlation between the tests, while in the "A" year football students the correlation between speed and strength $(r=-0.81)$ is distinguished.

Conclusions: It is noteworthy that the students of the first year of football as well as the specialists do not have as good results in endurance as compared to the students of the skiing, even though the football game lasts 90 minutes compared to Alpine skiing 1-2 minutes.

Keywords: physical abilities, alpine skiers, footballers, tests.
\end{abstract}

\section{Introduction}

Several researchers present the issue of diagnosing physical fitness and individual physical abilities through various tests outside the laboratory area, in racing conditions in winter sports e.g. in skiing, and in summer sports e.g. at football. By the term test of the skier (or footballer) we mean the tool that controls and measures the elements of the motor skills and physical abilities of the trainee from the technical or physical standpoint respectively, while the assessment and evaluation is done by the teacher or coach through the test result or "norm" [8]. Alpine skiing requires relatively slow eccentric and concentric movements that produce forces up to $3 \mathrm{G}$, lasting from 40 seconds to over two minutes. As the ultimate control of snow contact and the ability to limit speed distance requires dynamic balance through a wide range of mobility of the lower limbs and hips. Endurance and preparation should focus on hypertrophy, maximal endurance development, balance, dynamic mobility and anaerobic capacity [13]. Soccer is a highintensity sport that requires players with high levels of aerobic and anaerobic ability, force, velocity, power, skill, coordination and flexibility so as to become competitive [22]. Soccer is characterized by short sprints, rapid acceleration or deceleration, turning, jumping, kicking, and tackling [1, 3, 33] and are directly related with the power production capacity of the neuromuscular system. Soccer players, as well as many other athletes on the (c) Vasilios F. Giovanis, Panagiotis V. Vasileiou,

Evangelos M. Bekris, 2017

doi:10.15561/18189172.2017.0504 field and the court, execute multiple sprints during the course of a match [20]. The capacity of soccer players to produce varied high-speed actions is known to impact a soccer match performance [18], can be categorized into actions requiring maximum speed, acceleration, or agility [17] and are critical to the outcome of the game. During a typical game, a 2- to 4-second sprint occurs every 90 seconds $[2,23]$. Sprinting occupies some $3 \%$ of playing time and accounts for $1-11 \%$ of the distance covered during a match. Some $96 \%$ of sprints are shorter than $30 \mathrm{~m}$, and $49 \%$ are $10 \mathrm{~m}[15,26]$.

Purpose of the research

The purpose of this research was to diagnose physical abilities such as speed, strength, agility and endurance of alpine skiers and footballers through the same country test. Also, the purpose was to compare the performance and test result of the above tested against one another.

By performance, we mean the behavior of the tested person during the test (e.g technique, heart rate, etc.), while top result means the end result.

Research questions and assumptions

The enunciation of the assumptions was based on the following research questions:

1) Is there a comparison between alpine skiers and footballers?

2) If so, then which tests and physical abilities present the difference?

3) Is the difference due to the effect of training or other random factors?

4) Is there a criterion for selecting tests that can be a 
reliable "simulation" test for skiing or football?

Delimitation, restrictions and conditions

The measurements and constraints included in the survey were carried out in the same way: (a) in the same geographical area, in the same weather conditions and at the same time of day; (b) in a sample of individuals with the same characteristics as status, age and sex .

\section{Material and methods}

Participants:

The sample of 58 individuals came from two groups of men of different sports: skiing $(n=29)$ aged $18-26$ $(20.97 \pm 2.08$ years $)$ and football $(n=29)$ aged $18-25(21$, $28 \pm 1.56$ years), while the level in each group was the advanced and the beginner respectively.

The measuring instruments

In the physical abilities test, the following measuring instruments were used: timer with an accuracy of 0.01 $\mathrm{sec}, 20 \mathrm{~cm}$ height cones and $1 \mathrm{~mm}$ precision tape measure.

\section{Means of data collection}

The following tests are based on the general ICSPFT international test [9, 34] with eight general tests (it was released prior to the Eurofit test [6]) and the Haczkiewicz test $[12,16]$. The criterion for selecting a test was the result of the published research or the nominated research, which will answer if the test for skiing is valid and reliable $[21,31]$ and football $[28,29,30]$. Special tests of dry land in skiing were selected by researchers and authors, who presented the results of some tests with norms $[8,12,16]$.

\section{Measurement procedure}

Until the trials, the ski and football teams had a training program exercising physical abilities and skills three days a week for the specialties and one day a week the select skiing session and the compulsory football session according to the curriculum. The training program included methods and exercises of all forms: general, mimetic on dry ground and snow specific for skiing ([8, 9] and exercises of all forms for football [25]. In order to diagnose and compare the physical abilities of ski students and football students, the following four tests of Alpine skiing on dry ground [8, 9] were used after the ski season on this day in April 2014: A) Route Speed test (Route $20 \mathrm{~m}$ with flight start). We perform two attempts and count the best. B) Explosive power tests of the lower limbs (Eightfold with alternating tossing of feet). We make two efforts and measure the distance of the best effort. C) Agility Tests (Slalom's track on a "folder" $5 \mathrm{~m}$ x 5m). We are trying to make two consecutive rounds in one attempt. D) Anaerobic test (Jumping of an obstacle of $20 \mathrm{~cm}$ height by $60 \mathrm{sec})$. We measure the number of repetitions in an attempt (endurance to jumps).

Statistical analysis

Planning was implemented, where there were 4 research teams. For all characteristics of the tested, the mean (M) and the standard deviation (SD) were measured. The mean value of the test results per group in the individual tests has been correlated to each other by the following design: Test A with B, A-C, A-D, B-C, B-D and C-D. The statistical analysis was done with the Excel 2007 statistical program.

\section{Results}

\section{Analysis of anthropometric data}

The age, sex and the anthropometric characteristics of the ski and football teams that participated in the research are presented in Table 1 and Table 2. In the group of advanced skiers (Table 1) 11 were 22-26 year old specialty students $(22,64 \pm 1,21$ years $)$, height 1,70 $2,00 \mathrm{~m}(1,83 \pm 0,08)$ and weight $64-85 \mathrm{~kg}(75,45 \pm 7,59)$, whereas in the group of the beginners, 18 were students 18-23 years of age in the optional course $(19,94 \pm 1,83$ years $), 1,62-1,84 \mathrm{~m}(1,76 \pm 0,06)$ and weighing $65-100 \mathrm{~kg}$ $(75,83 \pm 9,51)$.

In the group of advanced football (Table 1), 14 were 22-25 year old specialty students $(22,29 \pm 0,04$ years $)$, height $1.64-1.82 \mathrm{~m}(1,76 \pm 0,05)$ and weighing $56-90 \mathrm{~kg}$ $(72,07 \pm 7,60)$. The body mass index (BMI) of the skiers had the following values: $24,46 \pm 2,45$ in the advanced and $22,69 \pm 1,87$ in the beginners, while the football team of the advanced and the beginners had the following corresponding values: $23,19 \pm 1,76$ and $23,14 \pm 1,87$.

Differences between the physical abilities of skiers and footballers

\section{Specialization teams}

In the physical fitness tests and individual physical abilities, the skiing specialty had better results in explosive power (“eightfold”) and anaerobic test (altitude endurance), while football specialty had better results in

Table 1. Anthropometric characteristics of skiers and footballers

\begin{tabular}{|c|c|c|c|c|c|c|c|c|c|}
\hline \multirow[t]{2}{*}{ TEAMS } & \multirow{2}{*}{$\begin{array}{l}\text { SAMPLE } \\
\mathrm{n}\end{array}$} & \multicolumn{2}{|l|}{$\begin{array}{l}\text { AGE } \\
\text { (years) }\end{array}$} & \multicolumn{2}{|c|}{$\begin{array}{l}\text { HEIGHT } \\
(\mathrm{m})\end{array}$} & \multicolumn{2}{|c|}{$\begin{array}{l}\text { WEIGHT } \\
(\mathrm{kg})\end{array}$} & \multicolumn{2}{|c|}{$\begin{array}{l}\text { BMI } \\
\left(\mathrm{kg} / \mathrm{m}^{2}\right)\end{array}$} \\
\hline & & $\mathbf{M}$ & SD & $\mathbf{M}$ & SD & $\mathbf{M}$ & SD & $\mathbf{M}$ & SD \\
\hline SPECIALIZATION SKIING & 11 & 22,64 & 1,21 & 1,83 & 0,08 & 75,45 & 7,59 & 24,46 & 2,45 \\
\hline $\begin{array}{l}\text { SELECTION } \\
\text { SKIING }\end{array}$ & 18 & 19,94 & 1,83 & 1,76 & 0,06 & 75,83 & 9,51 & 22,69 & 1,87 \\
\hline SUM & 29 & 20,97 & 2,08 & 1,80 & 0,08 & $75,, 69$ & 8,69 & 23,36 & 2,24 \\
\hline $\begin{array}{l}\text { SPECIALIZATION } \\
\text { FOOTBALL }\end{array}$ & 14 & 22,29 & 0,04 & 1,76 & 0,05 & 72,07 & 7,60 & 23,19 & 1,76 \\
\hline SELECTION FOOTBALL & 15 & 20 & 1,50 & 1,79 & 0,09 & 74,73 & 10,53 & 23,14 & 1,87 \\
\hline SUM & 29 & 21,28 & 1,56 & 1,78 & 0,08 & 73,45 & 9,18 & 23,16 & 1,79 \\
\hline
\end{tabular}


speed and agility (Table 2).

In the skiing specialty we have a great correlation between speed tests and other physical abilities and agility with endurance. In football specialty there was a great correlation between speed tests and strength and agility with strength (Table 3).

Selection teams

In fitness tests and individual physical abilities, optional skiing had better results in all tests with emphasis on anaerobic test (altitude endurance - Table 4). In optional skiing, we have a moderate correlation between the tests, while in the " $\mathrm{A}$ " year football students we can see the correlation between speed and strength (Table 5).

\section{Discussion}

Comparison of results between skiers and footballers

In the skiing specialty we have a great correlation between speed tests and other physical abilities and agility with endurance. In football's specialty there was a great correlation between speed tests and strength and agility with strength. In optional skiing, we have a moderate correlation between the tests, while in the A 'year's students the correlation between speed and strength is distinguished. It is noteworthy that the students of the first year of football as well as the specialists do not have as good results in endurance as compared to the students of the skiing, even though the football game lasts 90 minutes compared to Alpine skiing 1-2 minutes.

Comparison of study results with other surveys

In skiing:

The performance of alpine skiing is closely related to both aerobic and anaerobic ability. Gross, et al., [10, 11] have investigated the seasonal variation of maximum oxygen uptake and the rate of oxygen uptake among the top skiers. During the racing season, skiers greatly reduce strength training and weight use, while snow training is predominant. In order to substantiate the above assumption, the performance of the top men's athletes has been compared to intensive biking on a ramp, jumps (SJ, CMJ) before and after the racing season. The results of the above study were as follows: 1 ) the maximum oxygen uptake (VO2max) relative to body weight was higher in the pre-racing period (55,2 $\pm 5,2$ vs. $52,7 \pm 3,6 \mathrm{mlkgmin}$, $\mathrm{p}<0,01), 2$ ) on the respiratory limit (VT), the absolute and the relative percent of the work was similar, while the heart rate was slower, 3 ) the height of the jump was higher at SJ, $(47,4 \pm 4,4$ vs. $44,7 \pm 4,3 \mathrm{~cm}, \mathrm{p}<0,01)$ and in CMJ $(52,7 \pm 4,6$ vs. $50,4 \pm 5,0 \mathrm{~cm}, \mathrm{p}<0,01)$. Aerobic ability and leg strength were limited to the pre-competitive period and that the improvements observed were mainly due to the mid-competitive recovery from the exhaustion situation in the pre-competitive period. Staying at high altitude in

Table 2. Comparison of physical abilities between skiing and football specialization teams

\section{SPECIALTIES - STATISTICS' INDEXS}

\section{TESTS}

PHYSICAL ABILITIES

SKIING

FOOTBALL

Group with

(Measurement unit)

\begin{tabular}{|c|c|c|c|c|c|c|c|c|c|}
\hline & & $M$ & SD & $\begin{array}{l}r \\
(p<0,05)\end{array}$ & M & SD & $\begin{array}{l}r \\
(p<0,05)\end{array}$ & D & \\
\hline A & $20 \mathrm{~m}$ - Speed (sec) & 2,83 & 0,16 & $\begin{array}{l}A-B= \\
-0,64\end{array}$ & 2,68 & 0,25 & $\begin{array}{l}A-B= \\
-0,65\end{array}$ & 0,15 & Football \\
\hline B & $\begin{array}{l}\text { «Eightfold»- } \\
\text { Explosive power } \\
\text { (m) }\end{array}$ & 18,60 & 1,54 & $\begin{array}{l}A-C= \\
0,70 \\
A-D= \\
-0,64\end{array}$ & 17,93 & 1,89 & $\begin{array}{l}A-C= \\
0,43 \\
A-D= \\
-0,13\end{array}$ & 0,67 & Skiing \\
\hline C & Slalom - Agility (sec) & 25,11 & 1,16 & $\begin{array}{l}B-C= \\
-0,44\end{array}$ & 23,89 & 1,42 & $\begin{array}{l}B-C= \\
-0,69\end{array}$ & 1,22 & Football \\
\hline D & $\begin{array}{l}\text { Jumping } \\
60 \text { sec-Endurance } \\
\text { (number of } \\
\text { repetitions) }\end{array}$ & 92,73 & 20,77 & $\begin{array}{l}B-D= \\
0,39 \\
C-D= \\
-0,72\end{array}$ & 73,57 & 6,24 & $\begin{array}{l}B-D= \\
0,26 \\
C-D= \\
-0,39\end{array}$ & 19,16 & Skiing \\
\hline
\end{tabular}

Table 3. Correlation coefficient between tests in ski and football specialization teams

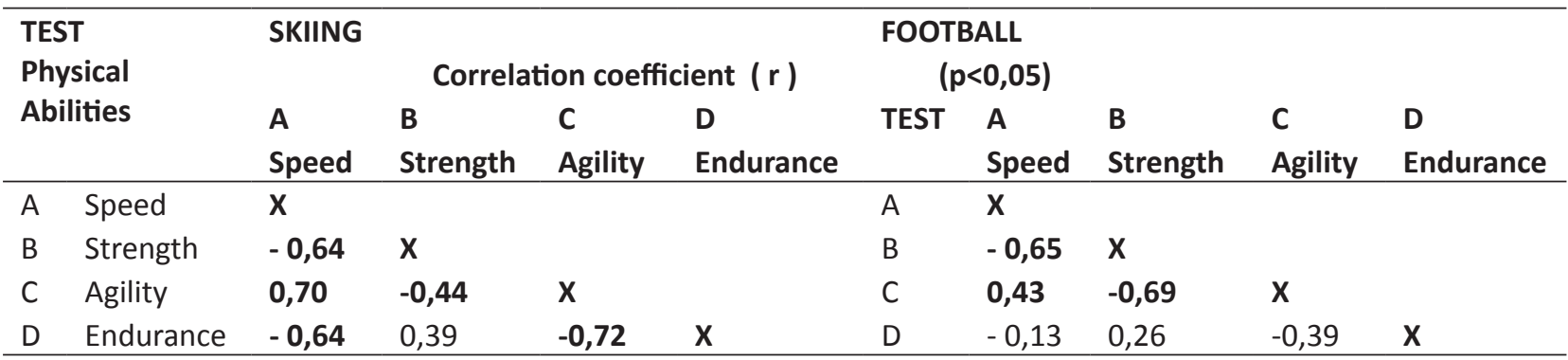


Table 4. Comparison of physical abilities between selection skiing and football teams

SELECTION - STATISTICS' INDEXS

\begin{tabular}{|c|c|c|c|c|c|c|c|c|c|}
\hline \multicolumn{2}{|c|}{$\begin{array}{l}\text { TESTS } \\
\text { PHYSICAL ABILITIES } \\
\text { (Measurement unit) }\end{array}$} & \multicolumn{2}{|c|}{ SKIING } & \multicolumn{4}{|c|}{ FOOTBALL } & \multirow{2}{*}{$\begin{array}{l}\text { Difference } \\
\text { D }\end{array}$} & \multirow[t]{2}{*}{$\begin{array}{l}\text { Group with } \\
\text { improved } \\
\text { performance }\end{array}$} \\
\hline & & M & SD & $\begin{array}{l}r \\
(p<0,05)\end{array}$ & $M$ & SD & $\begin{array}{l}r \\
(p<0,05)\end{array}$ & & \\
\hline A & $\begin{array}{l}20 \mathrm{~m}- \\
\text { Speed (sec) }\end{array}$ & 2,64 & 0,21 & $\begin{array}{l}A-B= \\
-0,44\end{array}$ & 2,87 & 0,13 & $\begin{array}{l}A-B= \\
-0,81\end{array}$ & 0,23 & Skiing \\
\hline B & $\begin{array}{l}\text { «Eightfold»- } \\
\text { Explosive power } \\
\text { (m) }\end{array}$ & 18,71 & 1,35 & $\begin{array}{l}A-C=0,01 \\
A-D= \\
-0,35\end{array}$ & 18,33 & 1,86 & $\begin{array}{l}A-C=0,58 \\
A-D= \\
-0,36\end{array}$ & 0,38 & Skiing \\
\hline C & $\begin{array}{l}\text { Slalom- } \\
\text { Agility (sec) }\end{array}$ & 24,89 & 1,62 & $\begin{array}{l}B-C= \\
-0,45\end{array}$ & 25,91 & 1,46 & $\begin{array}{l}B-C= \\
-0,42\end{array}$ & 1,02 & Skiing \\
\hline D & $\begin{array}{l}\text { Jumping } \\
60 \mathrm{sec}- \\
\text { Endurance } \\
\text { (number of } \\
\text { repetitions) }\end{array}$ & 94,54 & 10,22 & $\begin{array}{l}B-D= \\
-0,45 \\
C-D= \\
-0,47\end{array}$ & 74,27 & 6,18 & $\begin{array}{l}B-D= \\
-0,32 \\
C-D= \\
-0,56\end{array}$ & 20,27 & Skiing \\
\hline
\end{tabular}

Table 5. Correlation coefficient between the tests in the selection ski and football teams

\begin{tabular}{|c|c|c|c|c|c|c|c|c|c|c|}
\hline \multirow{4}{*}{\multicolumn{2}{|c|}{$\begin{array}{l}\text { TEST } \\
\text { Physical } \\
\text { Abilities }\end{array}$}} & \multirow{2}{*}{\multicolumn{4}{|c|}{$\begin{array}{l}\text { SKIING } \\
\text { CORRELATION COEFFICIENT ( } r \text { ) }\end{array}$}} & \multirow{2}{*}{\multicolumn{5}{|c|}{$\begin{array}{l}\text { FOOTBALL } \\
(p<0,05)\end{array}$}} \\
\hline & & & & & & & & & & \\
\hline & & \multirow{2}{*}{$\begin{array}{l}\text { A } \\
\text { Speed }\end{array}$} & \multirow{2}{*}{$\begin{array}{l}\text { B } \\
\text { Strength }\end{array}$} & \multirow{2}{*}{$\begin{array}{l}\text { C } \\
\text { Agility }\end{array}$} & \multirow{2}{*}{$\begin{array}{l}\text { D } \\
\text { Endurance }\end{array}$} & \multirow[t]{2}{*}{ TEST } & \multirow{2}{*}{$\begin{array}{l}\text { A } \\
\text { Speed }\end{array}$} & \multirow{3}{*}{$\begin{array}{l}\text { B } \\
\text { Strength }\end{array}$} & \multirow{3}{*}{$\begin{array}{l}\text { C } \\
\text { Agility }\end{array}$} & \multirow{3}{*}{$\begin{array}{l}\text { D } \\
\text { Endurance }\end{array}$} \\
\hline & & & & & & & & & & \\
\hline$A$ & Speed & $x$ & & & & $A$ & $x$ & & & \\
\hline B & Strength & $-0,44$ & $x$ & & & B & $-0,81$ & $x$ & & \\
\hline C & Agility & 0,01 & $-0,45$ & $x$ & & C & 0,58 & $-0,42$ & $x$ & \\
\hline D & Endurance & $-0,35$ & $-0,45$ & $-0,47$ & $x$ & D & $-0,36$ & $-0,32$ & $-0,56$ & $x$ \\
\hline
\end{tabular}

the pre-competitive season could also affect the results. Aerobic fitness and leg explosiveness can be maintained during the racing season, but may be jeopardized by heavy or excessive pre-competitive practice.

\section{At football:}

It is estimated that between 1000 and 1500 discrete movement changes occur within each match at a rate of every 5-6s, having a pause of 3s every $2 \min [14,22$, 27]. The starting speed (10-15 meters) is a necessary skill in the football game since it assists in claiming the ball, in the unmanned and generally gives an advantage to the appearance of qualitative aggressive and defensive actions, [14]. Surveys show that elite \& sub elite players stand out from the amateurs at $10 \mathrm{~m}$ but not at the speed of $30 \mathrm{~m}[5,2]$. Agility is often recognized as the ability to change direction and start and stop quickly [7] and has been proven as agility performance is a powerful factor that distinguishes them skill levels in soccer [24, 14, 19, 32]. At the high level (Premier League) the players performed the equivalent of $726 \pm 203$ turns during the match; $609 \pm 193$ of these being of $0^{\circ}$ to $90^{\circ}$ to the left or right [4].

\section{Conclusions - Proposals}

Based on the results of the above survey we can conclude that:

1) It is possible to diagnose and compare the tests in both sports.

2) Skiing Specialization has had better results in explosive power and endurance to jumps, while football specialty has had better results in speed and agility.

3) Selection Skiing has had better results in all tests with emphasis on endurance to jumps.

4) It is remarkable that the students of the " $\mathrm{A}$ " year football as well as the specialty do not have as good results in the endurance as compared to the students of the skiing, although the football game lasts 90 minutes compared to Alpine ski 1-2 minutes.

5) Appropriate and documented variety with a wide range of tests may be the test selection criterion that can be a reliable "simulation" test for skiing or football.

\section{Conflict of interests}

The authors declare that there is no conflict of interests. 


\section{References}

1. Arnason A, Sigurdsson SB, Gudmundsson A, Holme I, Engebretsen L, Bahr R. Physical fitness, injuries, and team performance in soccer. Med Scis Sports Exerc. 2004; 36: 278-285.

2. Bangsbo J, Norregaard L, Thorso F. Activity profile of competition soccer. Can J Sport Sci. 1991; 16: 110-116.

3. Bangsbo J, Michalsik L. Assessment of the physiological capacity of elite soccer players. In: W. Spinks, T. Reilly, and A. Murphy, eds. Science and Football IV. London: Routledge; 2002.

4. Bloomfield J, Polman R, O’Donoghue P. Physical demands of different positions in FA Premier League soccer. Journal of Sports Science and Medicine. 2007; 6: 63-70.

5. Cometti G, Maffiuletti NA, Pousson M, Chatard JC, Maffulli $\mathrm{N}$. Isokinetic strength and anaerobic power of elite, sub-elite and amateur French soccer players. Int J Sports Med. 2001; 22: 45-51.

6. Eurofit. European test of Physical Fitness. Brussels; 1988.

7. Gambetta V. How to develop sport-specific speed. Sports Coach. 1996; 19: 22-24.

8. Giovanis V. Skiing technique. Athens: 2006. (in Greek).

9. Giovanis V. Coaching in Alpine skiing. Athens; 2008. (in Greek).

10.Gross MA, Breil FA, Lehmann AD, Hoppeler H, Vogt M. Seasonal variation of VO 2 max and the VO2-work rate relationship in elite Alpine skiers. Med Sci Sports Exerc. 2009; 41: 2084-2089.

11. Gross M, Luthy F, Kroell J, Muller E, Hoppeler H, Vogt M. Effects of eccentric cycle ergometry in alpine skiers. Int $J$ Sports Med. 2010; 31: 572-576.

12.Haczkiewicz B. The measurement of physical fitness of junior skiers. Physical Culture and Sport. 1976; 12:1-15. (in Polish).

13.Hydren JR. Performance Changes During a Weeklong High Altitude Training Camp in Lowlander Youth Athletes. Master's Theses. University of Connecticut Graduate School; 2012.

14.Kaplan T, Erkmen N, Taskin H. The Evaluation of the running speed and agility performance in professional and amateur soccer players Journal of Strength and Conditioning Research. 2009; 23(3):774-778.

15.Kraemer WJ, Hakkinen K. Strength Training for Sport. London: Blackwell Science; 2002.

16.Krasicki S, Majoch T, Tokarz L. Cross-country skiing. Training program for children and young people. Warsaw: COS; 1995. (in Polish).

17.Little T, Williams AG. Effects of differential stretching protocols during warm-ups on high-speed motor capacities in professional soccer players. J Strength Cond Res. 2006; 20: 203-207.

18.Luhtanen P. Biomechanical aspects. In: B. Ekblom, ed. Football (Soccer). Oxford: Blackwell Scientific Publications; 1994.

19.Mujika I, Santisteban J, Impellizzeri FM, Castagna C. Fitness determinants of success in men's and women's football. $J$ Sports Sci. 2009; 27(2):107-114.

20.Newman MA, Tarpenning KM, Marino FE. Relationships between isokinetic knee strength, single-sprint performance, and repeated-sprint ability in football players. J Strength Cond Res. 2004; 18: 867-872.

21.Raschner Ch, Patterson C, Puhringer R, Platzer HP. Current trends in specific testing in elite alpine ski racers. $8^{\text {th }}$ Congress European College of Sport Science. Salzburg. 2003. P. 9-12.

22.Reilly T. Science and Soccer. Routledge: New York; 2003.

23.Reilly T, Thomas V. A motion analysis of work-rate in different positional roles in professional football match-play. J Hum Mov Stud. 1976; 2: 87-97.

24.Reilly T, Williams AM, Nevill A, Franks A. Amultidisciplinary approach to talent identification in soccer. J Sports Sci. 2000; 18(9):695-702.

25.Sotiropoulos A, Bekris E. Football and Science - A Multilateral Approach. Athens: 2012. (in Greek).

26.Stolen T, Chamari K, Castagna C, Wisloff U. Physiology of soccer: An update. Sports Med. 2005, 35: 501-536.

27.Strudwick A, Reilly T, Doran D. Anthropometric and fitness profiles of elite players in two football codes. Journal of Sports Medicine and Physical Fitness. 2002; 42: 239-242.

28.Talaga J. General physical fitness -Tests. Poznan; 2004. (in Polish).

29.Talaga J. Special physical fitness -Tests. Poznan; 2006. (in Polish).

30.Talaga J. ABC Young Player - Teaching Technique. Poznan; 2006. (in Polish).

31.Tchorzewski D. Verify Haczkiewicz's special performance test for his accuracy. Studia i monografie, 2015;31:131-137. (in Polish).

32.Vescovi JD, Rupf R, Brown TD, Marques MC. Physical performance characteristics of high-level female soccer players 12-21 years of age. Scand J Med Sci Sports. 2011; 21(5):670-678.

33.Wisloff U, Helgerud J, Hoff J. Strength and endurance of elite soccer players. Med Sci Sports Exerc. 1998, 30: 462-467.

34.Zak S. Scoreboards of the international Physical fitness test (ICSPFT) for youth 12-18 years old. Krakow; 1977. (in Polish). 


\section{Information about the authors:}

Giovanis Vasilios; http://orcid.org/0000-0003-2511-8286; vgiovan@phed.uoa.gr; School of Physical Education and Sport Science, National and Kapodistrian University of Athens; 41 Ethnikis Antistassis Str., Daphne 17237, Athens, Greece.

Vasileiou Panagiotis; http://orcid.org/0000-0003-2823-6093; panvas265@gmail.com; School of Physical Education and Sport Science, National and Kapodistrian University of Athens; 41 Ethnikis Antistassis Str., Daphne 17237, Athens, Greece.

Bekris Evangelos; http://orcid.org/0000-0001-5178-0391; vag_bekris@yahoo.gr; School of Physical Education and Sport Science, National and Kapodistrian University of Athens; 41 Ethnikis Antistassis Str., Daphne 17237, Athens, Greece.

Cite this article as: Giovanis V, Vasileiou P, Bekris E.. The diagnosis and comparison of physical abilities of skiers and footballers. Pedagogics, psychology, medical-biological problems of physical training and sports, 2017;21(5):221-226. doi:10.15561/18189172.2017.0504

The electronic version of this article is the complete one and can be found online at: http://www.sportpedagogy.org.ua/index.php/PPS/issue/archive

This is an Open Access article distributed under the terms of the Creative Commons Attribution License, which permits unrestricted use, distribution, and reproduction in any medium, provided the original work is properly cited (http://creativecommons.org/licenses/by/4.0/deed.en).

Received: 01.08.2017

Accepted: 25.08.2017; Published: 25.09.2017 